\section{Cureus}

\title{
Resection of Large Metachronous Liver Metastasis with Gastric Origin: Case Report and Review of the Literature
}

\author{
Ionut Negoi ${ }^{1}$, Alexandru Runcanu ${ }^{2}$, Sorin Paun ${ }^{2}$, Ruxandra Irina Negoi ${ }^{3}$, Mircea Beuran ${ }^{2}$ \\ 1. Carol Davila University of Medicine and Pharmacy, Bucharest, Bucharest, ROU 2. General Surgery \\ Department, Emergency Hospital of Bucharest, Carol Davila University of Medicine and Pharmacy \\ Bucharest 3. Anatomy and Embryology Department, Emergency Hospital of Bucharest, Carol Davila \\ University of Medicine and Pharmacy Bucharest
}

$\square$ Corresponding author: Ionut Negoi, negoiionut@gmail.com

Disclosures can be found in Additional Information at the end of the article

\section{Abstract}

Introduction: Increasing evidence suggests that surgical resection may be offered to a subgroup of patients with liver metastasis of gastric adenocarcinoma. The aim of this case report is to illustrate the surgical resection of a single liver metachronous recurrence twelve months after a radical total gastrectomy for cancer.

Case report: A 63-year-old male patient with an Eastern Cooperative Oncology Group performance status of 1 was referred to our hospital for a single, large liver metastasis, twelve months after a radical total gastrectomy and DII lymphadenectomy for upper third gastric adenocarcinoma. As the adjuvant treatment, the patient received 12 cycles of FOLFOX chemotherapy. During the present admission, the abdominal computed tomography (CT) revealed a single liver metastasis located in the segments 5 and 6, of 105/85 mm in diameter. Surgical resection by an open approach of liver metastasis was decided. We performed a nonanatomical liver resection, without inflow control due to significant peritoneal adhesions in the liver hilum secondary to the previous lymphadenectomy. The patient was discharged after seven days, with an uneventful recovery. Six months after the second surgical procedure, the patient developed a local liver recurrence. The surgical resection of the liver recurrence was performed, with no postoperative morbidities, and the patient was discharged after eight days. Three months after the latest surgery, the patient is under adjuvant chemotherapy, with no imagistic signs of further recurrences.

Conclusions: Hepatic resection for liver metastasis of gastric origin may offer satisfactory oncological outcomes in a very selected subgroup of patients.

Received 09/20/2016 Review began 09/28/2016 Review ended 09/28/2016 Published 10/03/2016

\section{(c) Copyright 2016}

Negoi et al. This is an open access article distributed under the terms of the Creative Commons Attribution License CC-BY 3.0., which permits unrestricted use, distribution, and reproduction in any medium, provided the original author and source are credited.
Categories: Gastroenterology, General Surgery, Oncology

Keywords: liver metastases, gastric cancer, metachronous resection, oligometastases

\section{Introduction And Background}

Gastric cancer continues to be an aggressive malignancy, with 107,000 deaths in 2012, representing the fourth cause of mortality from cancer in Europe [1]. In western countries, most of the patients with gastric cancer are diagnosed in at advanced stage, and this may explain the five-year overall survival of $25 \%$, compared to $70 \%$ reported in Japan [2]. Patients with metastatic disease present a dismal prognosis, with a reported median survival of four months in the case of best supportive care, and up to twelve months in the case of palliative

\section{How to cite this article}

Negoi I, Runcanu A, Paun S, et al. (October 03, 2016) Resection of Large Metachronous Liver Metastasis with Gastric Origin: Case Report and Review of the Literature . Cureus 8(10): e814. DOI 10.7759 /cureus. 814 


\section{Cureus}

chemotherapy [3]. Liver metastases from gastric cancer are present in $40 \%$ of patients dying from this disease [4]. However, these are rarely eligible for surgical resection, usually being multicentric or associated with extra-hepatic disease [5]. Data from retrospective studies with a relatively small number of subjects suggest that a subgroup of patients with gastric cancer and liver metastasis can be selected for surgery [6].

The objective of this case report is to illustrate the surgical resection of a liver metachronous recurrence twelve months after a radical resection for gastric cancer.

\section{Review}

\section{Case report}

A 63-year-old male patient with an Eastern Cooperative Oncology Group index of 1 was referred to our hospital for a single, large liver metastasis, twelve months after a radical total gastrectomy and DII lymphadenectomy for upper third gastric adenocarcinoma. The initial pathology report identified a pT3N1MOLV1, moderate-differentiated, gastric adenocarcinoma. As an adjuvant treatment, the patient received 12 cycles of FOLFOX chemotherapy. During the present admission, the abdominal computed tomography (CT) revealed a unique liver metastasis located in the segments 5 and 6, of 105/85 mm in diameter (Figure 1).

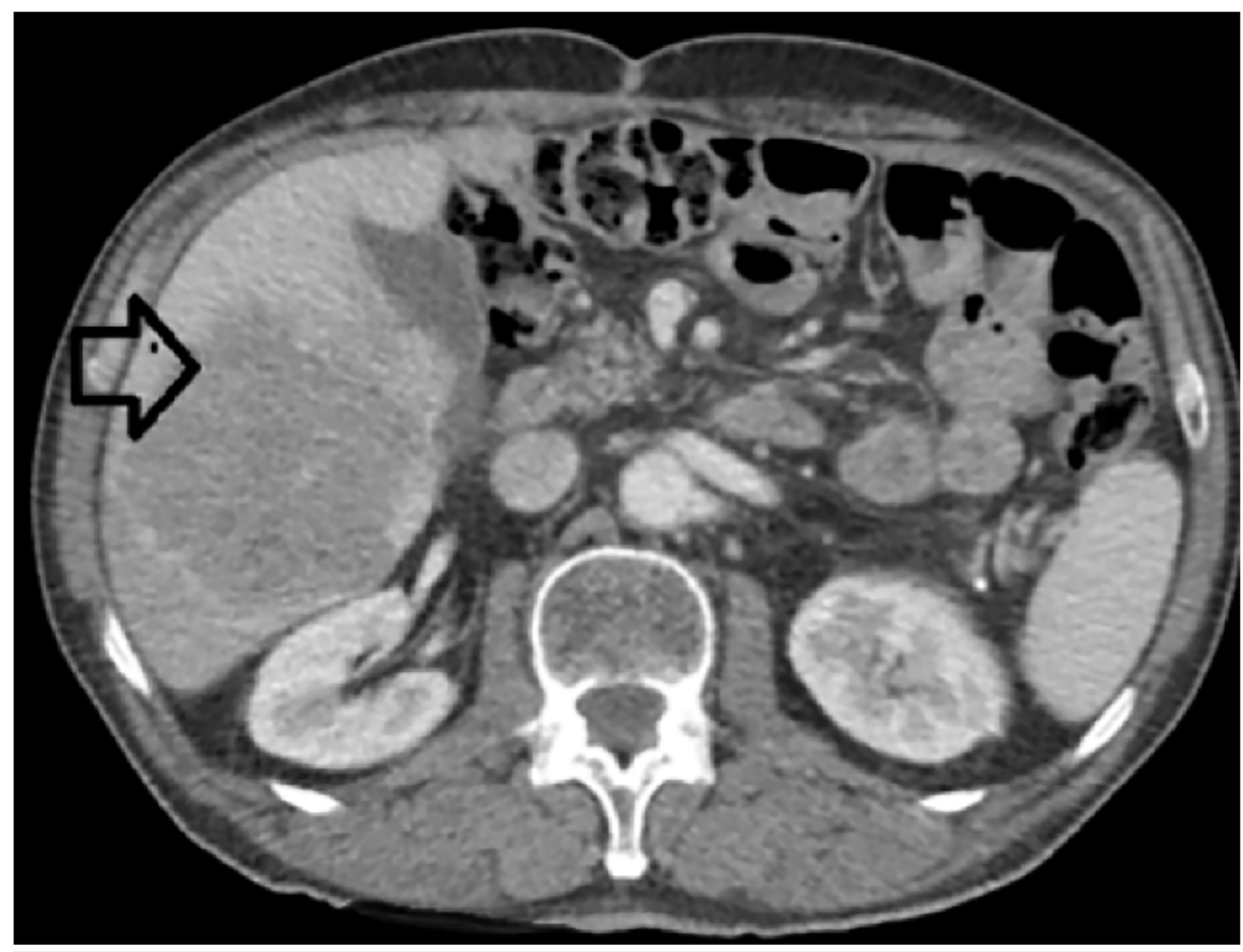

FIGURE 1: Computed Tomography Image Revealing a Single Liver Metastasis, Located in Segments 5 and 6 of the Liver

The 18-FDG PET-CT scan revealed no extrahepatic disease. Surgical resection by an open approach of liver metastasis was decided. The peritoneal washing revealed no malignant cytology, and intraoperative ultrasonography showed no additional liver metastatic disease. We performed a non-anatomical liver resection, without inflow control due to significant 


\section{Cureus}

peritoneal adhesions in the liver hilum, secondary to previous lymphadenectomy (Figure 2).

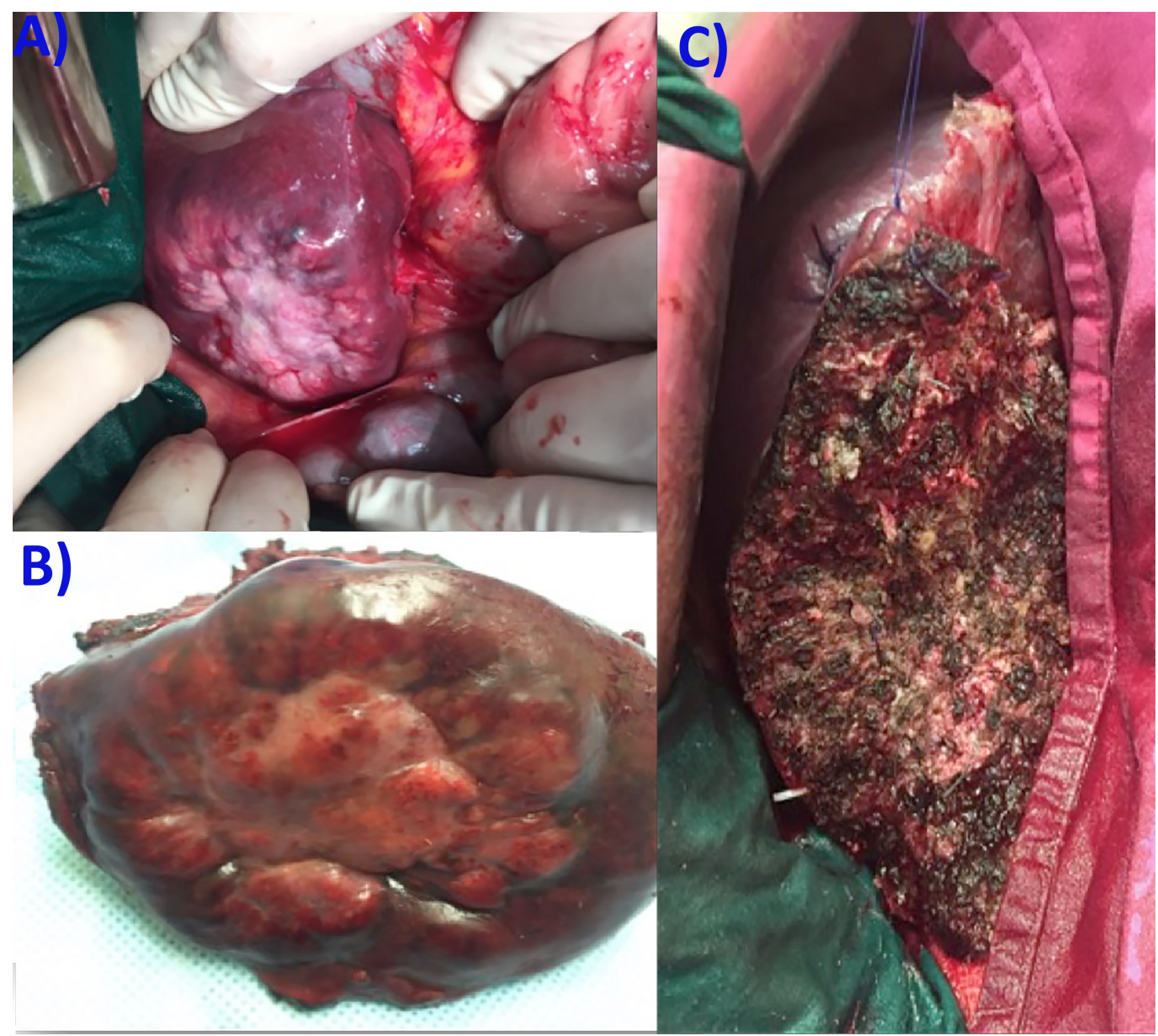

FIGURE 2: Intraoperative Aspects

(A) the liver metastasis, $(B)$ the resection specimen, and (C) the raw surface of the liver.

The patient was discharged after seven days, with an uneventful recovery. The pathology report confirmed metastatic disease with a gastric origin. Six months after the second surgical procedure, the patient developed a local liver recurrence, of $84 / 73 \mathrm{~mm}$ diameter. The thoracic, abdominal, and pelvic CT revealed no extrahepatic metastases. The surgical resection of the liver recurrence was performed, with no postoperative morbidities, and the patient was discharged after eight days. Three months after the latest surgery, the patient is under adjuvant chemotherapy, with no imagistic signs of additional recurrences.

\section{Discussions}

We presented a case of a surgical resection for a unique liver metachronous recurrence twelve months after a radical resection for gastric cancer.

Twenty-five to thirty percent of patients with radical gastrectomy for cancer will develop a metachronous liver metastasis, increasing the overall rate of hepatic involvement to 50\% [7]. The liver is the most common site for metastases in patients with gastric cancer. However, the reported rate of liver resection for gastric cancer liver metastasis is less than $1 \%$, due to the multiple, bilateral, and extrahepatic nature of the disease [8-9]. In high-volume tertiary centers, the hepatectomy for gastric cancer metastasis is performed in $7 \%$ of cases, compared to 
$12 \%$ for all types hepatic malignancies [10].

Oligometastases, usually defined as fewer than five metastases, should be differentiated from a more advanced state of the disease, with a significant metastatic burden [11-12]. Increasing evidence presents the oligometastatic state as an intermediate status, between localized stage and polymetastatic cancer [13]. The oligo-recurrence was defined as five or less metastatic or recurrent lesions, with a controlled primary tumor [14]. Our patient presented a single, large metastasis, diagnosed twelve months after the primary tumor resection. In this subgroup of patients, local therapies for metastatic disease may offer survival benefits, comparable with those for localized disease [13]. Lussier et al., identified patterns of microRNA expression in oligometastatic patients treated with high-dose radiotherapy [15]. They showed that microRNA-200c enhancement in an oligometastatic cell line resulted in polymetastatic progression [15]. Uppal et al., reported four microRNAs encoded in the 14q32 locus (microRNA127-5p, microRNA-369-3p, microRNA-544a, and microRNA-655-3p) that are associated with oligometastatic phenotype [16]. These oligomiRs have overlapped biological effects that converge on cell proliferation, migration, adhesion, and epithelial to mesenchymal transition [16-17].

Reddy et al., evaluated the outcomes of partial hepatectomy in 82 patients with non-colorectal non-neuroendocrine (NCRNE) liver metastases [18]. Only one of these patients had a gastric cancer metastasis. The authors reported a longer median overall survival for neuroendocrine (NE) metastases, but similar for NCRNE and colorectal (CR) metastases (44 months for both). The multivariable analysis showed that delay of a liver resection for at least six months and chemoradiotherapy after resection might be associated with an improved overall survival (OS) [18]. Martel et al., presented the results of a multicenter study which included 52 patients (seven with gastroesophageal origin) with non-colorectal, non-neuroendocrine, and nonsarcoma metastasis [19]. The five-year overall survival for patients with a liver metastasis of gastro-esophageal origin was $50 \%$, compared to $63 \%$ for a contemporary colorectal liver metastasis cohort [19]. Adam et al., developed a prognostic model for hepatic resection for NCRNE metastasis, starting from 1452 patients from 41 French centers [20]. R0 resection was obtained in $83 \%$ of cases, with a major complication rate of $21.5 \%$ and a 60 -day mortality of $2.3 \% .67 \%$ of patients have a tumor recurrence (24\%-liver, $18 \%$-extrahepatic, $25 \%$-both). Factors associated with poor prognosis were: age $>60$ years, non-breast origin, melanoma or squamous histology, disease free interval less than twelve months, extrahepatic metastases, R2 resection, and major hepatectomy [20]. Our patient had a local liver recurrence, diagnosed six months after the second surgery which was also amenable to surgical resection. Uggeri et al., published a systematic review of 30 articles, including 3849 patients, with surgical resection for non-colorectal, non-neuroendocrine and non-sarcoma metastasis [21]. The five-year OS of patients with liver metastasis of gastric and duodenal origin was 15\%-30\%. A worse five-year OS of less than $15 \%$ was observed in liver metastases of esophageal, cardiac, and pancreatic origin. Better outcomes were observed for liver metastasis with primary tumor located in the breast, kidney, uterus, ovary, ampulla of Vater, or adrenal glands, with a five-year OS greater than 30\% [21]. A review of 420 NCRNE patients from four major liver centers showed a recurrent disease in $66 \%$ of patients [22]. The multivariable analysis found as independent predictors of poorer survival the lymphovascular invasion and metastases $\geqslant 5 \mathrm{~cm}$. Although survival was not significantly different between various primary locations, it was significantly higher for cases managed between 2000-2009 compared with 1990-1999 (66 versus 32 months, $\mathrm{P}=0.003$ ) [22]. The analysis of 106 patients from five hepatobiliary and pancreatic centers from Argentina revealed that curative resections and metachronous disease were predictors for better survival [23]. Earle et al., showed that a longer interval of time between primary surgery and diagnoses of liver relapse is predictive of survival [24].

Takemura et al., reviewed 73 patients with surgical resection of gastric cancer liver metastases [25]. They showed one-, three-, and five-year survival rates for macroscopically complete 
resections of $84.5 \%, 50 \%$, and $37 \%$, respectively [25]. Two hundred fifty-seven patients with gastric cancer liver metastases from five Japanese centers, showed a mean number of resected tumors of two, with a surgical mortality of 1.6\% [26]. Seventy-five percent of patients had disease recurrence, especially in the liver (72.4\%) after a median interval of seven months [26]. It should be noted that even long-term survival may be obtained for very selected patients. Out of 42 patients presented by Koga et al., eight survived more than five years [27]. However, only a small subgroup of liver metastases of gastric origin may be selected for surgical resection. From 319 patients with Stage IV gastric cancer, only 17 were resected [28]. A multicentric Italian survey presented 73 patients with metachronous hepatic metastases from gastric carcinoma [29]. The three-year survival rate was $2.2 \%$ in the supportive care group, $6.4 \%$ in the chemotherapy group, and 20.2\% in the surgical group [29]. Markar et al., published the most recent meta-analysis regarding hepatectomy for metastases of gastric adenocarcinoma [30]. Thirty-nine studies published between 1990 - 2015 were included [30]. The pooled 30 morbidity and mortality were $24 \%$ (0\%-47\%) and $0 \%$ (0\%-30\%), respectively. The one-, three-, and fiveyear survival rates were $68 \%, 31 \%$, and $27 \%$, respectively. Surgical resection was associated with significant overall survival (hazard ratio $=0.5, \mathrm{P}<0.001$ ), especially for solitary lesions (odds ratio $=0.31, \mathrm{P}=0.011$ ) [30]. The were no differences between synchronous and metachronous metastasis resections $(\mathrm{P}=0.631)$ [31]. Another meta-analysis of 870 patients coming from 23 studies showed a five-year overall survival rate of 30\% (95\% confidence interval (CI) $24.7 \%$ to $35.8 \%$ ) and $22.6 \%$ (95\% CI $14 \%$ to $34.4 \%$ ) for metachronous and synchronous resections, respectively [32]. The parameters associated with poorer survival were multiple metastases and large size of the metastases (see Table 1). 


\section{Cureus}

\begin{tabular}{|c|c|c|c|c|c|}
\hline Study & Country & $\begin{array}{l}\text { Time } \\
\text { Interval }\end{array}$ & $\begin{array}{l}\text { Number of } \\
\text { Patients/Metachronuos } \\
\text { Metastasis }\end{array}$ & $\begin{array}{l}\text { 5-year } \\
\text { os }\end{array}$ & Predictive Factors for Poorer OS \\
\hline $\begin{array}{l}\text { Okano et al., } \\
2002[33]\end{array}$ & Japan & $\begin{array}{l}1986- \\
1999\end{array}$ & $19 / 6$ & $34 \%$ & $\begin{array}{l}\text { More than one nodule, Synchronous } \\
\text { disease }\end{array}$ \\
\hline $\begin{array}{l}\text { Koga et al., } \\
2007 \text { [27] }\end{array}$ & Japan & $\begin{array}{l}1985- \\
2005\end{array}$ & $42 / 22$ & $42 \%$ & $\begin{array}{l}{ }^{*} \text { Serosal invasion of primary GC, *More } \\
\text { than one nodule }\end{array}$ \\
\hline $\begin{array}{l}\text { Takemura et } \\
\text { al., } 2012 \text { [25] }\end{array}$ & Japan & $\begin{array}{l}1993- \\
2011\end{array}$ & $73(\mathrm{R} 0 / \mathrm{R} 1-64) / 32$ & $37 \%$ & $\begin{array}{l}{ }^{*} \text { Serosal invasion of primary GC, *Hepatic } \\
\text { tumor }>5 \mathrm{~cm}\end{array}$ \\
\hline $\begin{array}{l}\text { Garancini et } \\
\text { al., } 2012[34]\end{array}$ & Italy & $\begin{array}{l}1998- \\
2007\end{array}$ & $21 / 9$ & $19 \%$ & $\begin{array}{l}\text { More than one nodule, Positive margin, } \\
\text { Lack of peritumoral fibrous capsule }\end{array}$ \\
\hline $\begin{array}{l}\text { Aoyagi et al., } \\
2013 \text { [28] }\end{array}$ & Japan & $\begin{array}{l}1984- \\
2010\end{array}$ & $17 / 5$ & $17.60 \%$ & \\
\hline $\begin{array}{l}\text { Qiu et al., } 2013 \\
\text { [35] }\end{array}$ & China & $\begin{array}{l}1998- \\
2009\end{array}$ & $25 / 0$ & $29.40 \%$ & *More than one nodule \\
\hline $\begin{array}{l}\text { Kinoshita et al., } \\
2015 \text { [26] }\end{array}$ & Japan & $\begin{array}{l}1990- \\
2010\end{array}$ & 256/150 & $31.10 \%$ & $\begin{array}{l}{ }^{*} \text { Serosal invasion of primary } \mathrm{GC},{ }^{* 3} 3 \text { liver } \\
\text { metastases, }{ }^{*} \text { Hepatic tumor }>5 \mathrm{~cm}\end{array}$ \\
\hline
\end{tabular}

\section{TABLE 1: Studies Including Patients with Surgical Resection for Gastric Cancer Liver Metastasis}

OS - overall survival, * - results of multivariable analysis, GC - gastric cancer

Although the chemotherapy represents the mainstay of treatment for liver metastases of gastrointestinal malignancies (and for very selected cases surgical resection may be taken into account), it seems that stereotactic body radiation therapy (SBRT) may offer local control with acceptable toxicity [36]. Mendez Romero et al., reported 34 metastases--none with gastric origin, and 11 hepatocellular carcinomas treated with SBRT. Local control rates were $94 \%$ and $82 \%$ at one and two years, respectively [36]. Rusthoven et al., evaluated SBRT in a multiinstitutional study which included 47 patients with 63 liver metastases [37]. The one- and twoyear local control rates were $95 \%$ and $92 \%$, respectively, with a median survival of 20.5 months [37].

\section{Conclusions}

Based on our case report and previously reported data, we conclude that hepatic resection for liver metastasis of gastric origin may offer better oncological outcomes in a very selected subgroup of patients.

\section{Additional Information}

\section{Disclosures}

Conflicts of interest: In compliance with the ICMJE uniform disclosure form, all authors 
declare the following: Payment/services info: All authors have declared that no financial support was received from any organization for the submitted work. Financial relationships: All authors have declared that they have no financial relationships at present or within the previous three years with any organizations that might have an interest in the submitted work. Other relationships: All authors have declared that there are no other relationships or activities that could appear to have influenced the submitted work.

\section{References}

1. Ferlay J, Steliarova-Foucher E, Lortet-Tieulent J, et al.: Cancer incidence and mortality patterns in Europe: estimates for 40 countries in 2012. Eur J Cancer. 2013, 49:1374-1403. 10.1016/j.ejca.2012.12.027

2. De Angelis R, Sant M, Coleman MP, et al.: Cancer survival in Europe 1999-2007 by country and age: results of EUROCARE--5-a population-based study. Lancet Oncol. 2014, 15:23-34. 10.1016/s1470-2045(13)70546-1

3. Van Cutsem E, Sagaert X, Topal B, Haustermans K, Prenen H: Gastric cancer. Lancet. 2016, 10.1016/S0140-6736(16)30354-3

4. de Mestier L, Lardière-Deguelte S, Volet J, Kianmanesh R, Bouché O: Recent insights in the therapeutic management of patients with gastric cancer. Dig Liver Dis. 2016, 48:984-994. 10.1016/j.dld.2016.04.010

5. Waddell T, Verheij M, Allum W, et al.: Gastric cancer: ESMO-ESSO-ESTRO clinical practice guidelines for diagnosis, treatment and follow-up. Ann Oncol. 2013, 24 Supp 6:vi57-vi63. 10.1093/annonc/mdt344

6. Kodera Y, Fujitani K, Fukushima N, et al.: Surgical resection of hepatic metastasis from gastric cancer: a review and new recommendation in the Japanese gastric cancer treatment guidelines. Gastric Cancer. 2014, 17:206-212. 10.1007/s10120-013-0299-X

7. Mastoraki A, Benetou C, Mastoraki S, et al.: The role of surgery in the therapeutic approach of gastric cancer liver metastases. Indian J Gastroenterol. 2016, 10.1007/s12664-016-0683-7

8. Shirabe K, Wakiyama S, Gion T, et al.: Hepatic resection for the treatment of liver metastases in gastric carcinoma: review of the literature. HPB (Oxford). 2006, 8:89-92. 10.1080/13651820500472168

9. Grimes N, Devlin J, Dunne DFJ, Poston G, Fenwick S, Malik H: The role of hepatectomy in the management of metastatic gastric adenocarcinoma: a systematic review. Surg Oncol. 2014, 23:177-185. 10.1016/j.suronc.2014.08.001

10. Zacherl J, Zacherl M, Scheuba C, et al.: Analysis of hepatic resection of metastasis originating from gastric adenocarcinoma. J Gastrointest Surg. 2002, 6:682-689. 10.1016/S1091255X(01)00075-0

11. Milano MT, Katz AW, Zhang H, Okunieff P: Oligometastases treated with stereotactic body radiotherapy: long-term follow-up of prospective study. Int J Radiat Oncol Biol Phys. 2012, 83:878-886. 10.1016/j.ijrobp.2011.08.036

12. Weichselbaum RR, Hellman S: Oligometastases revisited. Nat Rev Clin Oncol. 2011, 8:378382. 10.1038/nrclinonc.2011.44

13. Huang F, Wu G, Yang K: Oligometastasis and oligo-recurrence: more than a mirage . Radiat Oncol. 2014, 9:230. 10.1186/s13014-014-0230-6

14. Niibe Y, Hayakawa K: Oligometastases and oligo-recurrence: the new era of cancer therapy . Jpn J Clin Oncol. 2010, 40:107-111. 10.1093/jjco/hyp167

15. Lussier YA, Xing HR, Salama JK, et al.: MicroRNA expression characterizes oligometastasis(es). PLoS One. 2011, 6:e28650. 10.1371/journal.pone.0028650

16. Uppal A, Wightman SC, Mallon S, et al.: 14q32-encoded microRNAs mediate an oligometastatic phenotype. Oncotarget. 2015, 6:3540-3552. 10.18632/oncotarget.2920

17. Beuran M, Negoi I, Paun S, et al.: The epithelial to mesenchymal transition in pancreatic cancer: A systematic review. Pancreatology. 2015, 15:217-225. 10.1016/j.pan.2015.02.011

18. Reddy SK, Barbas AS, Marroquin CE, Morse MA, Kuo PC, Clary BM.: Resection of noncolorectal nonneuroendocrine liver metastases: a comparative analysis. J Am Coll Surg. 2007, 204:372382. 10.1016/j.jamcollsurg.2006.12.019

19. Martel G, Hawel J, Rekman J, et al.: Liver resection for non-colorectal, non-carcinoid, nonsarcoma metastases: a multicenter study. PLoS One. 2015, 10:e0120569. 
10.1371/journal.pone.0120569

20. Adam R, Chiche L, Aloia T, et al.: Hepatic resection for noncolorectal nonendocrine liver metastases: analysis of 1,452 patients and development of a prognostic model. Ann Surg. 2006, 244:524-535. 10.1097/01.sla.0000239036.46827.5f

21. Uggeri F, Ronchi PA, Goffredo P, et al.: Metastatic liver disease from non-colorectal, nonneuroendocrine, non-sarcoma cancers: a systematic review. World J Surg Oncol. 2015, 13:191. 10.1186/s12957-015-0606-6

22. Groeschl RT, Nachmany I, Steel JL, et al.: Hepatectomy for noncolorectal non-neuroendocrine metastatic cancer: a multi-institutional analysis. J Am Coll Surg. 2012, 214:769-777. 10.1016/j.jamcollsurg.2011.12.048

23. Lendoire J, Moro M, Andriani O, et al.: Liver resection for non-colorectal, non-neuroendocrine metastases: analysis of a multicenter study from Argentina. HPB (Oxford). 2007, 9:435-439. 10.1080/13651820701769701

24. Earle SA, Perez EA, Gutierrez JC, et al.: Hepatectomy enables prolonged survival in select patients with isolated noncolorectal liver metastasis. J Am Coll Surg. 2006, 203:436-446. 10.1016/j.jamcollsurg.2006.06.031

25. Takemura N, Saiura A, Koga R, et al.: Long-term outcomes after surgical resection for gastric cancer liver metastasis: an analysis of 64 macroscopically complete resections. Langenbecks Arch Surg. 2012, 397:951-957. 10.1007/s00423-012-0959-z

26. Kinoshita T, Kinoshita T, Saiura A, Esaki M, Sakamoto H, Yamanaka: T. Multicentre analysis of long-term outcome after surgical resection for gastric cancer liver metastases. Br J Surg. 2015, 102:102-107. 10.1002/bjs.9684

27. Koga R, Yamamoto J, Ohyama S, et al.: Liver resection for metastatic gastric cancer: experience with 42 patients including eight long-term survivors. Jpn J Clin Oncol. 2007, 37:836-842. 10.1093/jjco/hym113

28. Aoyagi K, Kouhuji K, Kizaki J, Isobe T, Hashimoto K, Shirouzu K: Study of gastric cancer cases with liver metastasis. J Gastrointest Dig Syst. 2013, June 22: 10.4172/2161-069X.S12-017

29. Tiberio GA, Coniglio A, Marchet A, et al.: Metachronous hepatic metastases from gastric carcinoma: a multicentric survey. Eur J Surg Oncol. 2009, 35:486-491.

10.1016/j.ejso.2008.12.017

30. Markar SR, Mikhail S, Malietzis G, et al.: Influence of surgical resection of hepatic metastases from gastric adenocarcinoma on long-term survival: systematic review and pooled analysis. Ann Surg. 2016, 263:1092-1101. 10.1097/sla.0000000000001542

31. Tiberio GAM, Roviello F, Donini A, et al.: Surgery for liver metastasis from gastric cancer. . Clin Transl Gastroenterol. 2016, 1:10.21037/tgh.2016.08.02

32. Petrelli F, Coinu A, Cabiddu M, et al.: Hepatic resection for gastric cancer liver metastases: a systematic review and meta-analysis. J Surg Oncol. 2015, 111:1021-1027. 10.1002/jso.23920

33. Okano K, Maeba T, Ishimura K, et al.: Hepatic resection for metastatic tumors from gastric cancer. Ann Surg. 2002, 235:86-91. 10.1097/00000658-200201000-00011

34. Garancini M, Uggeri F, Degrate L, et al.: Surgical treatment of liver metastases of gastric cancer: is local treatment in a systemic disease worthwhile? . HPB (Oxford). 2012, 14:209-215. 10.1111/j.1477-2574.2011.00428.x

35. Qiu JL, Deng MG, Li W, et al.: Hepatic resection for synchronous hepatic metastasis from gastric cancer. Eur J Surg Oncol. 2013, 39:694-700. 10.1016/j.ejso.2013.03.006

36. Méndez Romero A, Wunderink W, Hussain SM, et al.: Stereotactic body radiation therapy for primary and metastatic liver tumors: A single institution phase i-ii study. Acta Oncol. 2006, 45:831-837. 10.1080/02841860600897934

37. Rusthoven KE, Kavanagh BD, Cardenes H, et al.: Multi-institutional phase I/II trial of stereotactic body radiation therapy for liver metastases. J Clin Oncol. 2009, 27:1572-1578. 10.1200/jco.2008.19.6329 